\title{
Um estudo sobre os aspectos textuais e terminológicos das certidões de casamento expedidas entre 1791 e 1916 na \\ França
}

\author{
A study on textual and terminological aspects of \\ marriage certificates issued between 1791 and 1916 in \\ France
}

\author{
Beatriz Curti-Contessoto* \\ Lidia Almeida Barros**
}

\begin{abstract}
RESUMO: Este artigo tem o objetivo de apresentar os resultados de nossa investigação sobre os aspectos textuais e terminológicos das certidões de casamento civil francesas expedidas entre os anos de 1791 e 1916. Para desenvolver este estudo, fundamentamo-nos no arcabouço teórico e metodológico da Terminologia, mais especificamente no da Terminologia Diacrônica. No que concerne à metodologia de nosso trabalho, primeiramente formamos um corpus composto por 127 certidões de casamento civil francesas que foram recolhidas graças a colaboradores e a sites especializados em árvores genealógicas. Observamos, em seguida, as ocorrências das unidades terminológicas e dos elementos textuais em cada documento ao longo do tempo em uma relação do tipo presença e ausência e comparamos os resultados.
\end{abstract}

PALAVRAS-CHAVE: Aspectos textuais; unidade terminológica; certidão de casamento civil.

ABSTRACT: This paper aims to present the results of an investigation of the textual and terminological aspects of French civil marriage certificates issued between 1791 and 1916. To develop this research, the theoretical and methodological assumptions of Terminology and Diachronic Terminology were adopted. Regarding the methodology of this work, a corpus was composed of 127 French civil marriage certificates that were collected thanks to collaborators and websites specializing in family trees. Then, the occurrences of the terminological units and textual elements were observed in this corpus. According to the dates of each document, their presence and absence were compared.

KEYWORDS: Textual aspects; terminological unit; civil marriage certificate.

* Pós-doutoranda da Universidade de São Paulo (USP), doutora pela Universidade Estadual Paulista (UNESP), bolsista da Fundação de Amparo à Pesquisa do Estado de São Paulo (FAPESP), bfcurti@gmail.com, https://orcid.org/0000-0002-5497-5589.

** Professora Titular da Universidade Estadual Paulista (UNESP), doutora pela Université Lumière Lyon 2, lidia.barros@unesp.br, https://orcid.org/o00o-0001-8944-4895. 


\section{Introdução}

Os textos se configuram como veículos por meio dos quais diferentes áreas de especialidade transmitem seus saberes. Por serem assim utilizados, eles apresentam traços que lhes são característicos em "nível sintático, semântico, pragmático, semiótico e, sobretudo, lexical, uma vez que é principalmente por meio de uma terminologia própria que esse tipo de texto veicula os conhecimentos especializados" (BARROS, 2007, p. 9). A nosso ver, essas características são específicas de cada área de especialidade e, além disso, são marcadas por questões culturais inerentes à comunicação.

Neste trabalho, o texto em estudo é a certidão de casamento, que é utilizada pelos cônjuges para comprovar diante do Estado e da sociedade a união constituída pelo casamento civil. Como todo documento jurídico, a certidão de casamento é regida por uma legislação que é própria de um país e é registrada em sua língua. Por ser representativa da visão de mundo de seus falantes, a língua é altamente marcada do ponto de vista cultural e, nesse sentido, as terminologias das áreas de especialidade também o são. A certidão de casamento é um dos tipos de documento que revela, por meio de sua terminologia e de suas características textuais, diversos aspectos sociais, políticos, históricos e culturais da comunidade na qual se insere.

Nesse sentido, interessou-nos estudar os aspectos textuais e terminológicos presentes em certidões de casamento civil francesas expedidas entre os anos de 1791 e 1916, a fim de verificar sua evolução em uma perspectiva diacrônica e sua relação com aspectos socioculturais e históricos da França relativos a esse período. É importante dizer que determinamos o final do século XVIII como ponto de partida de nossas buscas, uma vez que o casamento civil foi instituído nesse período (1791).

Para realizar este estudo ${ }^{24}$, baseamo-nos nos pressupostos teóricos e metodológicos da Terminologia (BARROS, 2004, 2007; KRIEGER, FINATTO,

\footnotetext{
24 Este estudo recebeu apoio financeiro da FAPESP.
} 


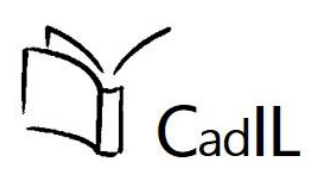

2004; dentre outros), mais especificamente nos da Teoria Comunicativa da Terminologia (TCT), sistematizada por Cabré (1999). No que tange às questões socioculturais que subjazem aos aspectos textuais e terminológicos das certidões de casamento civil francesas, baseamo-nos em estudos sobre a História da França e do Direito francês. A seguir, apresentamos os pressupostos teóricos adotados nesta investigação.

\section{Fundamentação teórica}

No âmbito de nossa pesquisa, consideramos que o termo terminologia é constituído por dupla-significação: "ele tanto pode significar os termos técnicocientíficos, representando o conjunto das unidades lexicais típicas de uma área científica, técnica ou tecnológica, quanto o campo de estudos” (KRIEGER; FINATTO, 2004, p. 13). Assim sendo, adotamos terminologia, neste trabalho, nesses dois sentidos. Para diferenciá-los, a acepção de campo de estudos das terminologias será grafada com $T$ maiúsculo, e a acepção de conjunto de termos por meio dos quais os textos das áreas de especialidades exprimem seus conceitos será expressa com $t$ minúsculo.

A Terminologia se debruça sobre diversos aspectos, dentre os quais estão as chamadas linguagens de especialidade, as quais podem ser definidas como "sistemas de comunicação oral ou escrita usados por uma comunidade de especialistas de uma área particular do conhecimento" (PAVEL; NOLET, 2003, p. 124). As linguagens de especialidade possuem um léxico especializado por meio do qual uma determinada área do saber transmite seus conhecimentos.

Fundamentando-nos na TCT, assumimos, em nossa pesquisa, que o estatuto de termo é atribuído a uma unidade lexical graças às condições pragmáticas que têm o objetivo de adequá-la a um determinado tipo de comunicação realizado no âmbito de um domínio de especialidade (CABRÉ, 1999). Além disso, consideramos que os termos "são unidades linguísticas que devem ser consideradas em uma perspectiva poliédrica, ou seja, em seus aspectos 
linguísticos, cognitivos e sociais"2 (CABRÉ, 1993, p. 123). Nesse sentido, entendemos que se trata de "uma unidade linguística, cuja expressão e conteúdo são inseparáveis (signo linguístico/unidade linguística)”(CURTI-CONTESSOTO, 2019, p. 36) e que, ao ser veiculada no contexto comunicacional de determinado domínio de especialidade, torna-se uma unidade terminológica. Seu conteúdo representa um conceito que é entendido, no âmbito deste trabalho, como "uma unidade de pensamento constituída por abstração com base em características, traços, atributos ou propriedades comuns a uma classe de objetos, de relações ou de entidades, podendo esse conceito ser expresso por um termo ou por um símbolo" (BARROS, 2007, p. 37).

Neste trabalho, o levantamento das unidades terminológicas recorrentes em certidões de casamento francesas, bem como dos aspectos textuais inerentes a esse tipo de documento, deu-se sobre um corpus textual, aqui entendido como um "conjunto de textos selecionados que serve de base para uma análise terminológica” (PAVEL; NOLET, 2003, p. 119). Assim, foi com base na observação de suas ocorrências em um tipo específico de texto especializado que identificamos os aspectos aqui analisados.

De acordo com Hoffmann (1998), "o texto especializado é o instrumento ou o resultado de uma atividade comunicativa socioprodutiva especializada" (KRIEGER, FINATTO, 2004, p. 113). Assim, "a linguagem de especialidade não se resume à presença de termos técnicos, mas constitui-se do conjunto de todos os recursos linguísticos que se utilizam em um âmbito de comunicação" (KRIEGER, FINATTO, 2004, p.113).

Para Hoffmann (1998), os elementos de todos os níveis linguísticos (sons, letras, frases), bem como os mecanismos de organização do texto, por exemplo, fazem parte desses recursos (KRIEGER, FINATTO, 2004, p. 113). Além desses elementos, consideramos que outros itens que constam em certos tipos de texto, tais como timbres, símbolos e selos, por exemplo, que ocorrem em certidões de casamento, também caracterizam os textos em que aparecem, configurando-se

2 Tradução dessa citação feita por Krieger e Finatto (2004, p. 57). 
em recursos cuja compreensão é importante para um melhor entendimento do texto e do conjunto terminológico do domínio em estudo.

Enquanto texto jurídico que tem o fim de provar a existência de casamentos civis diante do Estado e da sociedade franceses, a certidão de casamento registra todos os dados dos cônjuges, dos pais de ambos e das testemunhas, e tudo o que aconteceu durante o ato do casamento, bem como o caso de alguém ter se pronunciado contra a realização do matrimônio. Por ser um ato público, o casamento civil deve ser celebrado com as portas da mairie abertas e cada noivo deve apresentar ao menos uma testemunha, desde que todas possuam idade igual ou superior a 18 anos. Durante a celebração, o responsável faz as leituras aos futuros esposos das disposições do Código Civil concernentes ao ato após ter confirmado a identidade de cada um deles e também das testemunhas. Eles lhe dão o consentimento e, caso não haja oposição por parte de terceiros, o responsável assina a certidão de casamento, que permanecerá guardada no acervo da mairie onde foi realizada a cerimônia. Por fim, ele entrega aos casados o livret de famille, uma espécie de "livrinho" que reúne os documentos pessoais da família (cópias autenticadas das certidões de nascimento e casamento, por exemplo) e informações a respeito dos direitos conferidos à instituição familiar, tais como filiação, adoção, divórcio (ou separação) e falecimento de um dos cônjuges ou de um filho menor de idade (FRANÇA, 2013a).

A cópia de uma certidão de casamento civil francesa pode ser requerida pelo casal diretamente na mairie onde se realizou essa união ou via on-line sob três formas (FRANÇA, 2013b). Duas delas são a copie intégrale (cópia integral) e o extrait d'acte de mariage avec filiation (um tipo de via da certidão de casamento que apresenta a filiação do casal), que contêm as informações concernentes a cada cônjuge (nome, sobrenome, data e local de nascimento), sobre os ascendentes (pais) e descendentes (filhos), sobre os herdeiros, sobre a data do casamento, sobre o regime matrimonial constado no pacto antenupcial e sobre dados adicionais, se houver (a aquisição de nacionalidade francesa, o divórcio, falecimento, dentre outros). A terceira forma se chama extrait d'acte de mariage sans filiation, que é uma via da certidão de casamento francesa que não 
traz a informação referente à filiação, apresentando apenas as informações concernentes aos cônjuges (nome, sobrenome, data e local de nascimento) e dados adicionais, caso existam.

Neste estudo, cumpre dizer que selecionamos apenas as certidões de tipo copie intégrale. Para nós, esses documentos são "aqui analisados como gêneros textuais ${ }^{25}$, ou seja, como formas de comunicação estabelecidas e conhecidas que circulam na esfera do Direito" (PEREIRA; NADIN, 2019, p. 129). Nesse sentido, entendemos que esses textos, tais como outros que circulam nesse domínio de especialidade, "tornam-se objetos que revelam a materialização do discurso jurídico" (PEREIRA; NADIN, 2019, p. 129).

Uma vez que esta investigação se deu sobre documentos com datas de expedição que contemplam um período de tempo de cerca de 120 anos, fundamentamo-nos também na Terminologia Diacrônica. Essa vertente considera que, além dos fenômenos de redução e de expansão de um termo ou de uma terminologia existentes, as unidades terminológicas, bem como os conceitos denominados por elas, podem aparecer e desaparecer por influência de mudanças socioculturais e históricas de um povo (CURTI-CONTESSOTO; BARROS, 2018). Assim, por um lado, certos termos e conceitos se tornam obsoletos e caem, portanto, em desuso. Por outro, terminologias e conceitos que acompanham a "evolução" da sociedade são criados ao longo do tempo.

Consideramos ainda que, além da evolução lexical, semântica e sintática pela qual passam as unidades terminológicas, outros recursos que fazem parte da estrutura de um documento jurídico, tais como símbolos e selos, por exemplo, podem sofrer alterações com o passar dos anos.

Com base nesses pressupostos, propomo-nos a observar os aspectos textuais e terminológicos das certidões de casamento expedidas entre 1793 e 1916 na França, a fim de verificar se esses documentos sofreram mudanças em termos de estrutura e como essas transformações podem ter influenciado a terminologia empregada nesse tipo de documento. Objetivamos ainda investigar a relação

\footnotetext{
25 Por gêneros textuais, entendemos "as formas comunicativas que, no contexto jurídico, são consolidadas" (PEREIRA; NADIN, 2019, p. 129).
} 
entre essas modificações e as questões socioculturais, políticas e históricas desse país que emergiram nesse período. $\mathrm{Na}$ seção a seguir, apresentamos a metodologia empregada para realizarmos nossas análises.

\section{Metodologia}

Para realizar esta investigação, constituímos um corpus formado por 127 certidões de casamento civil expedidas entre 1793 e 1916, doravante CCFCorpus. Consideramos que a quantidade de documentos selecionada foi suficiente para nossa pesquisa, uma vez que essas certidões são consideradas raras em virtude de sua antiguidade.

No que tange às fontes de nossas buscas para encontrar esses documentos, valemo-nos da Internet, mais especificamente de sites e blogs que trazem informações relativas a famílias ou que são especializados no registro de árvores genealógicas $^{26}$. Na maior parte dos casos, os documentos foram disponibilizados pelos próprios membros da família, deixando registrada na Internet a sua história.

Uma vez que grande parte das certidões se encontrava disponibilizada em arquivo de imagem, optamos por transcrevê-las, a fim de criarmos um corpus único e textual para observarmos a variação no nível lexical. Como código de reconhecimento de cada certidão, estabelecemos a sigla CCF[ANO] para Certidão de Casamento Francesa, acrescida de seu ano de expedição. Embora todas as certidões de casamento que analisamos sejam de domínio público, preferimos omitir, na transcrição, as informações pessoais presentes em sua redação. Para tanto, estabelecemos que essas informações seriam substituídas por [x] e que utilizaríamos [?] nas partes ilegíveis do documento.

Para realização de nossas análises em uma perspectiva diacrônica, consideramos que "as aparições e os desaparecimentos das ocorrências de certos termos ao longo do tempo constituem a mais simples manifestação de mudança.

${ }^{26}$ Exemplos de fontes consultadas: Durand (2017), Geneagrosne (2013) e Geneaservice (2013). 
Eles são medidos por uma informação do tipo presença/ausência” (TARTIER, 2006, p. 348, tradução nossa 27). Assim, observamos as ocorrências dos termos nas certidões de casamento francesas de nosso corpus, considerando os anos de expedição desses documentos, atentando-nos aos casos que sofreram alterações do ponto de vista sintático e lexical.

À luz dessa proposta de Tartier (2006), que é voltada para estudos da evolução dos termos em uma perspectiva diacrônica, verificamos também os aspectos textuais das certidões. Essa verificação se deu mediante a nossa observação do tipo presença/ausência desses aspectos nos documentos de nosso corpus de estudo.

\section{Resultados}

Na França, a celebração dos casamentos oficiais, bem como a expedição do documento que oficializava as uniões matrimoniais, ficou sob responsabilidade das instituições religiosas até 1791, quando se instaurou o casamento civil. Após essa data, passaram a coexistir casamentos civis (oficiais e obrigatórios) e casamentos religiosos (opcionais).

Nossas análises sobre os aspectos textuais e terminológicos das certidões de casamento compreendem o período de 1791 a 1916, ou seja, após a instituição do casamento civil. Assim, consideramos apenas os documentos que, diante do Estado, oficializavam os matrimônios nesse período, tendo como marco a Revolução Francesa (1789-1799), que possibilitou a instituição do casamento civil nesse país.

O primeiro aspecto textual que observamos em nossas pesquisas diz respeito ao carimbo que geralmente ocorre no canto superior esquerdo nos documentos de nosso corpus. A título de ilustração, apresentamos quatro

\footnotetext{
${ }_{27}$ "Les apparitions et disparitions d'attestations de certains termes au cours du temps constituent la manifestation la plus simple du changement. Elles se mesurent par une information de type présence/absence."
} 
certidões, expedidas respectivamente em 1802, 1837, 1859 e 1901, com enfoque em sua parte inicial.

Figura 1 - Parte de uma certidão de casamento civil expedida em $1802^{28}$

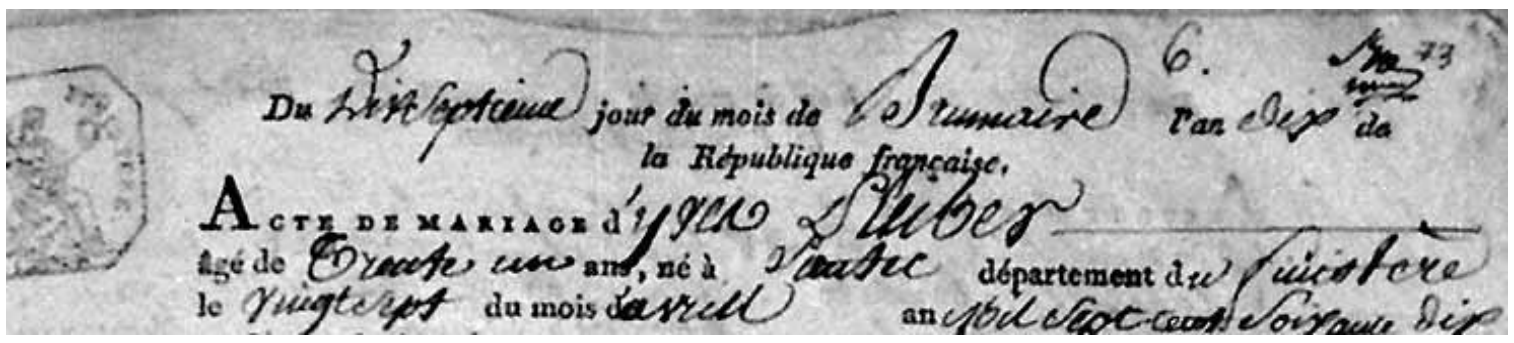

Fonte: Geneagrosne (2013, adaptado).

Figura 2 - Parte de uma certidão de casamento civil expedida em $1837^{29}$

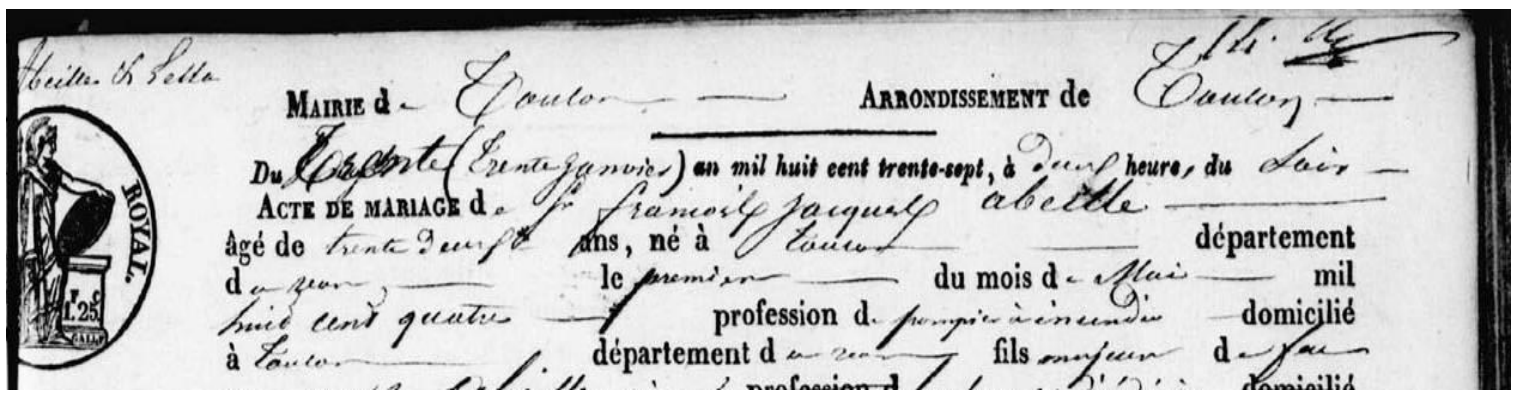

Fonte: Geneaservice (2013, adaptado).

Figura 3 - Parte de uma certidão de casamento civil expedida em $1859^{30}$

${ }^{28}$ No carimbo à esquerda, lê-se: REPUBLIQUE FRANÇAISE.

29 No carimbo à esquerda, lê-se: TIMBRE ROYAL.

$3^{\circ}$ No carimbo à esquerda, lê-se: TIMBRE IMPERIAL. 


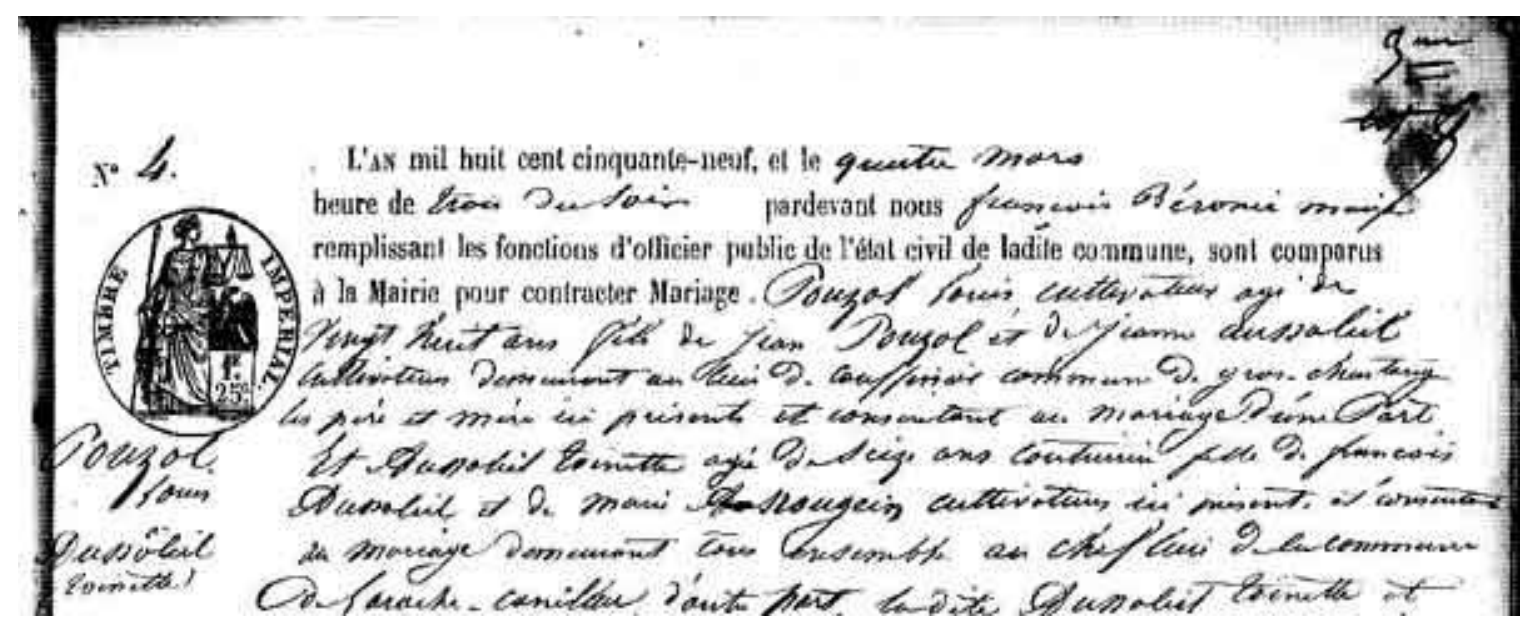

Fonte: Durand (2017, adaptado).

Figura 4 - Parte de uma certidão de casamento civil expedida em $1901^{31}$

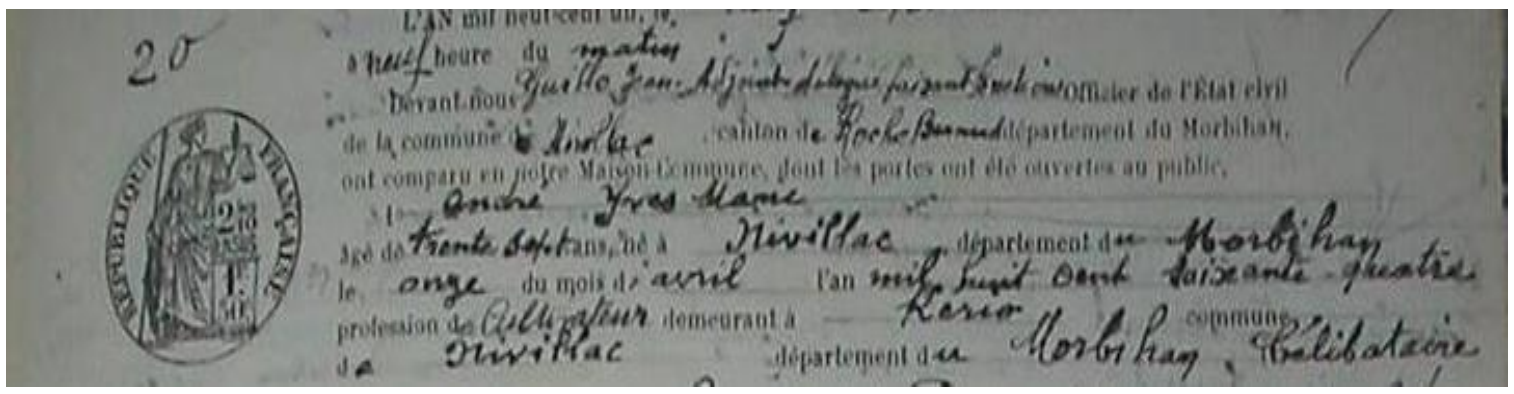

Fonte: Martinejude (2013, adaptado).

Como vemos, há uma diferença entre os carimbos desses documentos. Esses elementos textuais indicam o regime de governo mantido na França, representado pelo sistema judiciário na época da expedição de cada uma dessas certidões.

Em 1792, a Convenção Nacional decretou a abolição da realeza e instituiu uma república na França (FRANÇA, 2017). A Primeira República permaneceu em vigor até o ano de 1804, quando Napoleão Bonaparte, por meio de um golpe de Estado, instaurou o Império. Assim sendo, entendemos que esse fato explica a ocorrência de République Française em certidões expedidas entre 1792 e 1805.

${ }^{31}$ No carimbo à esquerda, lê-se: REPUBLIQUE FRANÇAISE. 
Até o ano de 1830, a França viveu sucessivas trocas de governo. Nesse ano especificamente, foi iniciado o Reinado de Luís Filipe I, o rei dos franceses, que durou até 1848. Desse modo, as certidões expedidas nesse período trazem uma referência a esse regime de governo, como vemos em timbre royal na Figura 2.

Em 1852, Napoleão Bonaparte implantou um novo regime: o Segundo Império francês. Seu governo se manteve em vigor de 1852 a 1869. Assim, a ocorrência de timbre impérial em certidões de casamento expedidas nesse período, tal como observamos na Figura 3, evoca esse momento da história da França.

Após essa fase, iniciou-se nesse país um novo regime governamental que ficou conhecido como Terceira República (1870-1940). Consequentemente, as certidões de casamento expedidas nesse período apresentam o carimbo République française, como vemos na Figura 4.

Isso posto, entendemos que os termos République française, timbre royal e timbre impérial, ao serem registrados nesses documentos, deixaram a marca dos diferentes regimes de governos existentes na história da política francesa. République française, por sua vez, refere-se a momentos diferentes da República nesse país.

Outro elemento que observamos é a mudança do calendário romano para o calendário republicano, influenciada pela instauração da República na França (1792). Proposta por Billaud-Varennes, essa alteração consistiu na adoção da contagem dos meses e dos anos tendo como ponto de referência o dia 21 de setembro de 1792 e foi inspirada na agricultura da França (FROESCHLÉCHOPARD; FROESCHLÉ-CHOPARD, 1990, p. 75). A título de explicação,

vejamos a etimologia dos três primeiros meses do ano, que compõem o outono. A do primeiro é tirada das vindimas, que ocorrem de setembro a outubro: esse mês se chama Vendemiário [Vendémiaire]. A do segundo, das névoas e brumas baixas de outubro e novembro: esse mês se chama Brumário [Brumaire]. $\mathrm{O}$ terceiro, do frio, às vezes seco, às vezes úmido, que reina de novembro a dezembro: esse mês se chama Frimário [Frimaire]. O primeiro dos três meses do inverno tira sua etimologia da neve que embranquece a terra de dezembro a janeiro: esse mês se chama Nivoso [Nivôse]. O segundo, das chuvas que caem generosamente em maior abundância de janeiro a fevereiro: esse mês se chama Pluvioso [Pluviôse]. O terceiro, o das pancadas de chuva e do 
vento que vem secar a terra de fevereiro a março, chama-se Ventoso [Ventôse]. O primeiro dos três meses da primavera tira sua etimologia da germinação e da subida da seiva de março a abril: esse mês se chama Germinal [Germinal]. O segundo, do desabrochar da floresta de abril a maio: esse mês se chama Floreal [Floréal]. $O$ terceiro, da fecundidade risonha e da colheita nos prados de maio a junho: esse mês se chama Prairial [Prairial]. O primeiro mês do verão, por fim, tira sua etimologia das espigas ondulantes e das messes douradas que cobrem os campos de junho a julho: esse mês se chama Messidor [Messidor]. O segundo, do calor solar e terrestre ao mesmo tempo, que abrasa o ar de julho até agosto: esse mês se chama Termidor [Thermidor]. O terceiro, dos frutos que o sol doura e amadurece de agosto a setembro: esse mês se chama Frutidor [Fructidor]. (SABORIT, 2009, p. 135)

Seguindo essa tipologia, observamos a data do registro da certidão de casamento civil que expomos anteriormente na Figura 1, a saber: "du dixseptième jour du mois de Brumaire l'an dix de la République française". Vemos que se trata do mês republicano Brumário do $10^{\circ}$ ano da República, ou seja, o segundo mês do outono francês, dez anos após a convenção que instaurou a República na França. Esse calendário se manteve vigente até o ano 1804 (CURTI; BARROS, 2016).

No que tange ao local de celebração e de registro dos casamentos civis, notamos a ocorrência de vários termos. A título de ilustração, vejamos o quadro a seguir:

Quadro 1 - Locais em que se celebraram e registraram os casamentos civis na França

\begin{tabular}{|c|c|}
\hline Documento & Excerto do documento \\
\hline CCF1791 & $\begin{array}{l}\mathrm{N}^{\mathrm{O}}[\mathrm{x}] \text { MARIAGE. Mairie d [x], Canton d [x], Arrondissement } \\
\text { communal d [x]. Du [x] jour du Mois d [x] l'An [x], à [x] heure du } \\
\text { (matin ou après-midi). ACTE DE MARIAGE d (a) [x], né à }[\mathrm{x}] \text {, } \\
\text { département d [x] le [x], du mois d }[\mathrm{x}] \text {, an }[\mathrm{x}] \text {, demeurant à }[\mathrm{x}] \text {, } \\
\text { département d }[\mathrm{x}] \text {, fils (b) d [x], demeurant à }[\mathrm{x}] \text {, département d } \\
{[\mathrm{x}](\ldots) \text {. }}\end{array}$ \\
\hline $\mathrm{CCF} 1$ & $\begin{array}{l}\text { (...) Le }[\mathrm{x}] \text { du mois de }[\mathrm{x}] \text { l'an }[\mathrm{x}] \text { de la république, a }[\mathrm{x}] \text {, dans la } \\
\text { salle publique de la maison commune, par devant moi officier } \\
\text { public soussigné, sont comparus }[\mathrm{x}] \text {, exerçant la profession de }[\mathrm{x}] \text {, } \\
\text { âgé de }[\mathrm{x}] \text { ans }[\mathrm{x}] \text { mois, natif de la municipalité de }[\mathrm{x}] \text {, district de } \\
{[\mathrm{x}] \text {, département de }[\mathrm{x}] \text {, fils naturel \& légitime de }[\mathrm{x}] \text {, exerçant la }} \\
\text { profession de }[\mathrm{x}] \text { \& de }[\mathrm{x}] \text { conjoints, demeurant à }[\mathrm{x}] \text { d'une part } \\
\text { (...). }\end{array}$ \\
\hline
\end{tabular}




\begin{tabular}{|l|l|}
\hline CCF1855 & $\begin{array}{l}\text { (...) RÉPUBLIQUE FRANÇAISE / Liberté - Égalité - Fraternité / } \\
\text { PREFECTURE DU DEPARTEMENT DE LA [x] / ACTE DE } \\
\text { MARIAGE (...). }\end{array}$ \\
\hline CCF1904 & $\begin{array}{l}\text { (...) L'an mil neuf cent quatre, le [x] [x], à [x] heures du [x] devant } \\
\text { nous, [x], adjoint délégué pour remplir en l'absence du Titulaire } \\
\text { les fonctions de [x] Maire et l'Officier de l'État civil de la commune } \\
\text { du [x], arrondissement de [x], déartement des [x], étant en } \\
\text { l'Hôtel-de-Ville, sont comparus (...). }\end{array}$ \\
\hline
\end{tabular}

Fonte: Elaborado pelos autores (grifos nossos).

Como vemos, os termos mairie, salle publique, maison commune, préfecture e Hôtel-de-Ville denominam os locais de celebração e de registro desses casamentos civis. Maison commune e hôtel-de-ville denominam a "sede da mairie, do conseil e dos serviços municipais" (ATILF, 2020, tradução nossa ${ }^{32}$ ). Logo, é o local em que se encontra a mairie, que é o órgão público responsável pelo Service d'État civil na França que celebra e registra os casamentos civis e expede as certidões.

O termo préfecture, por sua vez, chamou-nos a atenção pelo falo de não lidar com os casamentos na França, já que é o responsável pelo "conjunto de serviços da administração dos departamentos franceses” (CILF, 2020, tradução nossa33). No entanto, sua ocorrência em nosso corpus indica que, nesse contexto específico, denomina o local de celebração de registro de um casamento civil.

No CCFCorpus, observamos ainda as ocorrências dos termos que denominam os agentes que celebraram e registraram os casamentos civis ao longo da história da França. Vejamos alguns exemplos no quadro a seguir:

Quadro 2 - Agentes que celebraram e registraram os casamentos civis na França

\begin{tabular}{|l|l|}
\hline Documento & Excerto do documento \\
\hline CCF1793 & $\begin{array}{l}\text { (..) Le }[\mathrm{x}] \text { du mois de }[\mathrm{x}] \text { l'an }[\mathrm{x}] \text { de la république, a [x], dans la } \\
\text { salle publique de la maison commune, par devant moi officier } \\
\text { public soussigné, sont comparus [x], exerçant la profession de }[\mathrm{x}], \\
\\
\text { âgé de [x] ans [x] mois, natif de la municipalité de [x], district de }\end{array}$ \\
\hline
\end{tabular}

32 "Siège de la mairie, du conseil et des services municipaux."

33 "Ensemble des services de l'administration départementale." 


\begin{tabular}{|c|c|}
\hline & $\begin{array}{l}{[\mathrm{x}] \text {, département de }[\mathrm{x}] \text {, fils naturel \& légitime de }[\mathrm{x}] \text {, exerçant la }} \\
\text { profession de }[\mathrm{x}] \text { \& de }[\mathrm{x}] \text { conjoints, demeurant à }[\mathrm{x}] \text { d'une part ; } \\
\text { (...). }\end{array}$ \\
\hline CCF1837 & 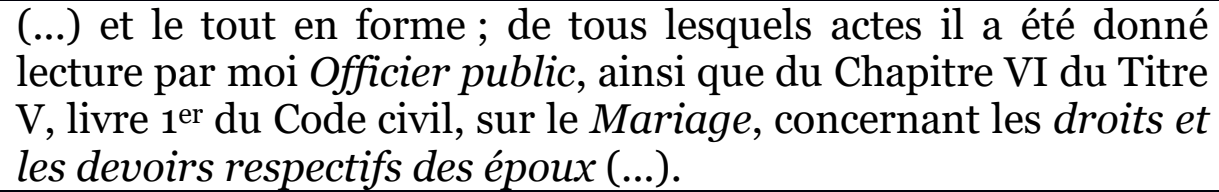 \\
\hline CCF1904 & $\begin{array}{l}\text { (...) L'an mil neuf cent quatre, le }[\mathrm{x}][\mathrm{x}] \text {, à }[\mathrm{x}] \text { heures du }[\mathrm{x}] \text { devant } \\
\text { nous, }[\mathrm{x}] \text {, adjoint délégué pour remplir en l'absence du Titulaire } \\
\text { les fonctions de }[\mathrm{x}] \text { Maire et l'Officier de l'État civil de la } \\
\text { commune du }[\mathrm{x}] \text {, arrondissement de }[\mathrm{x}] \text {, déartement des }[\mathrm{x}] \text {, } \\
\text { étant en l'Hôtel-de-Ville, sont comparus (...). }\end{array}$ \\
\hline $\mathrm{CCF} 1960$ & $\begin{array}{l}\text { (...) Lecture faite et invites à lire l'acte, les époux, la mère de } \\
\text { l'épouse et les témoins ont signé avec nous, [x], Adjoint au Maire } \\
\text { de [x], Officier de l'état civil par délégation. }\end{array}$ \\
\hline
\end{tabular}
Fonte: Elaborado pelos autores (grifo nosso).

Como vemos, officier public, adjoint, maire e officier de l'État civil são as unidades terminológicas que denominam os agentes responsáveis pelo serviço de celebrar e registrar os casamentos civis. Eles são representantes legais do Estado e, por isso, tem o poder de oficializar as uniões matrimoniais nesse país. Nossas observações de nosso corpus indicam que, desde a instituição do casamento civil na França em 1791 até 1916, não houve mudança com relação a esses agentes.

Outro aspecto que notamos em nossas análises diz respeito à legislação que trata dos casamentos civis na França ao longo do tempo. Para elucidar essa questão, vejamos o quadro a seguir:

Quadro 3 - Menção à legislação que trata dos casamentos civis na história da França

\begin{tabular}{|l|l|}
\hline Documento & Excerto do documento \\
\hline CCF1805 & $\begin{array}{l}\text { (...) Le tout en forme : de tous lesquels actes il a été donné lecture } \\
\text { par moi Officier public, aux termes de la Loi, du chapitre six du } \\
\text { titre du mariage (...). }\end{array}$ \\
\hline CCF1837 & $\begin{array}{l}\text { (...) et le tout en forme ; de tous lesquels actes il a été donné } \\
\text { lecture par moi Officier public, ainsi que du Chapitre VI du Titre } \\
\text { V, livre 1er du Code civil, sur le Mariage, concernant les droits et } \\
\text { les devoirs respectifs des époux (...). }\end{array}$ \\
\hline
\end{tabular}




\begin{tabular}{|l|l|}
\hline CCF1859 & $\begin{array}{l}\text { (...) et du chapitre VI du titre Mariage sur les droits et les devoirs } \\
\text { respectifs des époux, (...). }\end{array}$ \\
\hline CCF1904 & $\begin{array}{l}\text { (...) nous leur avons donné lecture des actes ci-dessous } \\
\text { mentionnés et du chapitre VI du Titre V du Code civil intitulé : } \\
\text { Des Droits et Devoirs respectifs des Époux (...). }\end{array}$ \\
\hline CCF1908 & $\begin{array}{l}\text { (...) nous ayant été remis, il en a été donné lecture, ainsi que du } \\
\text { chapitre VI du tivre V } \text { du Code Civil, intitulé du MARIAGE. (...). }\end{array}$ \\
\hline
\end{tabular}

Fonte: Elaborado pelos autores (grifo nosso).

No Quadro 3, vemos que a legislação que trata a matéria é a mesma em todos os documentos, embora seu modo de apresentação varie. Em outros documentos, porém, notamos que a lei em si não é mencionada, mas é retomada apenas por meio de expressões, tais como as que apresentamos a seguir:

Quadro 4 - Expressões que se referem à legislação dos casamentos civis na França

\begin{tabular}{|l|l|}
\hline Documento & Excerto do documento \\
\hline CCC1798 & $\begin{array}{l}\text { (...) et j'ai prononcé au nom de la Loi que [x] et [x] sont unis en } \\
\text { mariage. }\end{array}$ \\
\hline CCC1803 & $\begin{array}{l}\text { (...) Les actes préliminaires sont extraits des registres des } \\
\text { publications de mariage faites à [x] les [x] et [x] et affichés aux } \\
\text { termes de la Loi (...). }\end{array}$ \\
\hline
\end{tabular}
Fonte: Elaborado pelos autores (grifo nosso).

Como vemos, as expressões au nom de la loi e aux termes de la loi retomam a legislação, sem mencioná-la explicitamente, como o fazem os outros documentos mencionados anteriormente no Quadro 3.

Com relação à organização das informações nas certidões, notamos que um mesmo padrão foi seguido nos documentos de nosso corpus. A título de exemplificação, tomemos documento exposto a seguir: 
Figura 5 - Certidão de casamento civil expedida em 1908

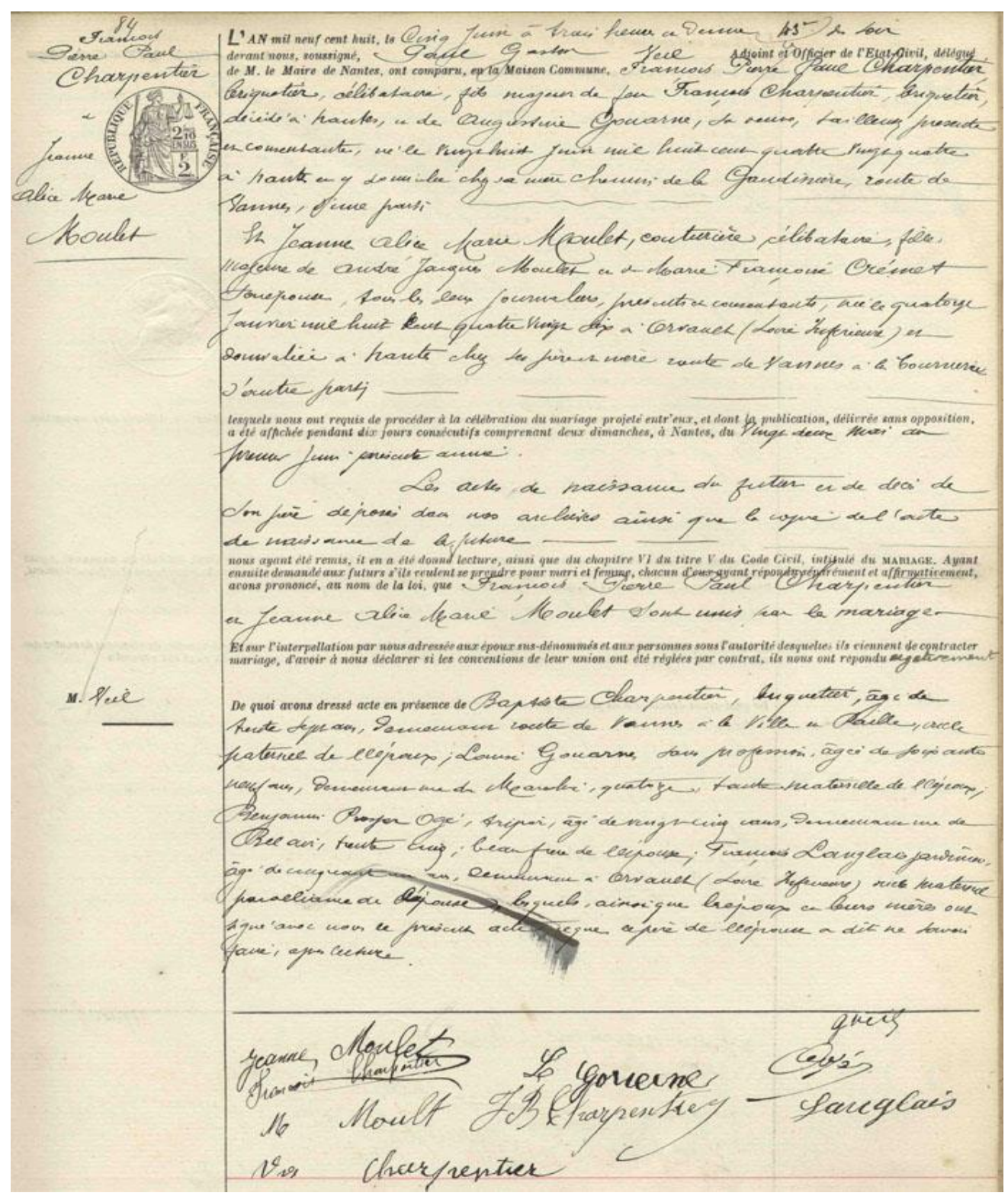

Fonte: FRANÇA (2010).

A Figura 5 nos apresenta uma certidão de casamento francesa em que os nomes dos cônjuges foram escritos em letra cursiva próximos ao carimbo da República Francesa em seu canto esquerdo. No topo e disposto de modo centralizado, o documento se inicia com a data em que ocorreu a celebração do matrimônio, escrita em letra cursiva seguindo a ordem ano-dia-mês-horário e com o nome do Officier de l'État Civil designado para realizar o casamento na 
Maison Commune escolhida. Em seguida, a certidão nos informa os nomes, sobrenomes, estado civil e filiação referentes ao noivo (futur) e à noiva (future). Vemos que o documento explicita que a celebração foi requerida pelos futuros esposos e que a publicação foi feita conforme a lei e nos dias informados. Apesar da dificuldade para compreendermos a letra cursiva, notamos que o oficial registrou que os documentos necessários para comprovação das informações referentes aos noivos, tais como as certidões de nascimento de ambos e a certidão de óbito do pai do noivo, foram devidamente apresentados.

Em seguida, o oficial fez as leituras prescritas pela lei (chapitre VI du Code Civil, intitulé du MARIAGE) e indagou aos noivos se era da vontade deles se tornarem mari (marido) e femme (mulher). Após a resposta afirmativa de cada um, o oficial os declarou unidos pelo casamento. Quanto à interpelação se eles haviam realizado um contrato pré-nupcial, sua resposta foi negativa. Por fim, o documento apresenta os dados referentes àqueles que presenciaram a cerimônia, terminando com as assinaturas dos mesmos, dos noivos, dos seus pais e do oficial, a fim de manifestarem sua concordância com o ato e o seu registro na presente certidão.

Embora a disposição das informações seja a mesma em todas as certidões de casamento que compõem o nosso corpus, verificamos uma variação no nível lexical. A título de exemplificação, vejamos o quadro a seguir:

Quadro 5 - Termos referentes aos dados dos cônjuges

\begin{tabular}{|c|c|}
\hline Documento & Excerto do documento \\
\hline CCF1793 & $\begin{array}{l}\text { (...) Le }[\mathrm{x}] \text { du mois de }[\mathrm{x}] \text { l'an }[\mathrm{x}] \text { de la république, a }[\mathrm{x}] \text {, dans la } \\
\text { salle publique de la maison commune, par devant moi officier } \\
\text { public soussigné, sont comparus }[\mathrm{x}] \text {, exerçant la profession de }[\mathrm{x}] \text {, } \\
\text { âgé de }[\mathrm{x}] \text { ans }[\mathrm{x}] \text { mois, natif de la municipalité de }[\mathrm{x}] \text {, district de } \\
{[\mathrm{x}] \text {, département de }[\mathrm{x}] \text {, fils naturel \& légitime de }[\mathrm{x}] \text {, exerçant la }} \\
\text { profession de }[\mathrm{x}] \& \text { de }[\mathrm{x}] \text { conjoints, demeurant à }[\mathrm{x}] \text { d'une } \\
\text { part (...). }\end{array}$ \\
\hline CCF1805 & $\begin{array}{l}\text { (...) Acte de Mariage de }[\mathrm{x}] \text {, âgé de }[\mathrm{x}] \text { ans, né à }[\mathrm{x}] \text { Département } \\
\mathrm{du}[\mathrm{x}] \text { le }[\mathrm{x}] \text { du mois de }[\mathrm{x}] \text { an }[\mathrm{x}] \text { profession de }[\mathrm{x}] \text { demeurant à } \\
{[\mathrm{x}] \text { Département d }[\mathrm{x}] \text { fils }(e) \text { majeur de }[\mathrm{x}](\ldots) \text {. }}\end{array}$ \\
\hline CCF1837 & (...) Les contractants ont déclaré prendre en mariage (...). \\
\hline
\end{tabular}




\begin{tabular}{|l|l|}
\hline CFF1854 & $\begin{array}{l}\text { (...) sont comparus : } 1^{\mathrm{O}}[\mathrm{x}] \text { âgé de }[\mathrm{x}][\mathrm{x}] \text { ans, profession de }[\mathrm{x}], \\
\text { natif de }[\mathrm{x}], \text { domicilié à }[\mathrm{x}], \text { fils majeur de }[\mathrm{x}](\ldots) .\end{array}$ \\
\hline CCF1859 & $\begin{array}{l}\text { (...) nous avons demandé au futur et à la future s'ils veulent se } \\
\text { prendre pour mari et pour femme }(\ldots) \text { nous avons demandé aux } \\
\text { futurs époux et au personnes qui autorisent le mariage, ici } \\
\text { présentes, s'il a été fait un contrat de mariage (...) Lesquels, après } \\
\text { qu'il leur a été donné lecture de cet acte, l'ont signé avec nous et } \\
\text { les parties contractantes }(. . .) .\end{array}$ \\
\hline
\end{tabular}

Fonte: Elaborado pelos autores (grifo nosso).

No Quadro 5, vemos que houve uma variação no modo como foram apresentadas algumas informações sobre os noivos. Dentre elas, destacamos o local de nascimento (natif(ve) de la municipalité, né(e) à e natif(ve) de), a filiação (fils naturel et légitime e fils(le) majeur(e) de) e o domicílio (demeurant(e) à e domicilié(e) à). Observamos ainda o uso de diferentes termos que denominam os noivos (contractants, futur(e), futurs époux e parties contractantes).

\section{Considerações finais}

Com base em nossas análises, verificamos que houve alterações no que concerne aos aspectos textuais e terminológicos das certidões de casamento francesas no período de 1791 a 1916. Essas alterações se observam nos carimbos, na forma de datação e na disposição das informações e das leis que tratam dos casamentos civis.

De fato, os diferentes carimbos encontrados, tais como République française, timbre royal e timbre impérial, evidenciam diferentes momentos da política da França. As sucessivas mudanças de regimes de governo são um aspecto sociocultural e histórico desse país que subjaz a essas unidades terminológicas.

Por sua vez, a mudança do calendário romano para o calendário republicano reflete os ideais da Revolução Francesa, que também se caracteriza em outro aspecto sociocultural muito específico desse país. Esse aspecto subjaz a outras ocorrências de nosso corpus, tais como aos termos que denominam os 
agentes envolvidos (officier public, adjoint, maire e officier de l'État civil) e os locais de celebração e de registro dos casamentos civis e de expedição das certidões (mairie, salle publique, maison commune, préfecture e Hôtel-de-Ville). Esses agentes e esses locais representam o Estado francês e marcam em sua expressão a laicidade do Estado, que foi um dos fortes ideais defendidos pela Revolução Francesa.

Outro aspecto observado diz respeito à legislação que trata dos casamentos civis na França. Notamos que os documentos registraram a mesma lei, Chapitre VI du Titre V, livre $1^{\text {er }} d u$ Code civil, sur le Mariage, variando apenas o modo de sua apresentação. Em outros documentos, constam expressões que retomam essa legislação, tais como au nom de la loi e aux termes de la loi.

Os diferentes termos e expressões utilizados para apresentar algumas informações sobre os cônjuges também nos chamaram a atenção. As ocorrências que encontramos em nosso corpus foram as seguintes: natif(ve) de la municipalité, né(e) à e natif(ve) de (para o local de nascimento), fils(le) naturel(le) et légitime e fils(le) majeur(e) de (para a filiação) e demeurant(e) à e domicilié(e) à (para o domicílio). Observamos ainda o uso de diferentes unidades terminológicas, tais como contractants, futur(e), futurs époux e parties contractantes, para denominarem os noivos.

Embora existam alterações com relação aos aspectos textuais e terminológicos nas certidões de casamento de nosso corpus, verifica-se um padrão no que tange à sua elaboração e à organização das informações que nelas são apresentadas. Ou seja, manteve-se um padrão quanto a esse aspecto durante os 125 anos contemplados em nosso estudo.

Enfim, salientamos que estudos como este podem auxiliar em uma melhor comunicação na área em pauta, na medida em que reúnem informações que podem colaborar com especialistas e com tradutores, por exemplo. Análises sobre a evolução dos termos, do ponto de vista lexical e semântico, que ocorrem nesses documentos pretendem ser discutidas de modo mais aprofundado em trabalhos futuros. 


\section{Referências}

Analyse et Traitement Informatique de la Langue Française (ATILF). Le Trésor de la Langue Française Informatisé, 2020. Disponível em: http://atilf.atilf.fr/. Acesso em: 18 ago. 2020.

BARROS, Lidia Almeida. Curso Básico de Terminologia. São Paulo: Editora da Universidade de São Paulo, 2004.

BARROS, Lidia Almeida. Conhecimentos de Terminologia geral para a prática tradutória. São José do Rio Preto, SP: NovaGraf, 2007.

CABRÉ, María Teresa. La terminologia: teoría, metodologia, aplicaciones. Barcelona: Editorial Antátida/Empúries, 1993.

CABRÉ, Maria Teresa. La terminología: representación y comunicación: elementos para una teoría de base comunicativa y otros artículos. Barcelona: IULA, 1999.

Conseil International de la Langue Française (CILF). Base de Terminologie, 2014. Disponível em: http://www.cilf.org/bt.fr.html. Acesso em: 06 mar. 2014.

CURTI, Beatriz Fernandes; BARROS, Lidia Almeida. A terminologia referente ao local de expedição das certidões de casamento francesas: um olhar sobre seus aspectos socioculturais. Domínio de Lingu@agem, v. 10, n. 3, 2016, p. 834-850. Disponível em: http://dx.doi.org/10.14393/DL23-v1on3a2016-4. Acesso em: 27 out. 2017.

CURTI-CONTESSOTO, Beatriz; BARROS, Lidia Almeida. Termos denominativos dos conceitos de rompimento e de dissolução do casamento na história do Brasil. Revista Digital Internacional de Lexicología, Lexicografía y Terminología (ReDILLeT), v. 1, p. 72-85, 2018. Disponível em: https://revistas.unc.edu.ar/index.php/ReDILLeT/article/view/22229. Acesso em: 29 jan. 2019.

CURTI-CONTESSOTO, Beatriz Fernandes. 2019. Terminologia de certidões de casamento: estudo terminológico bilíngue e elaboração de glossário portuguêsfrancês. 2019. Tese (Doutorado em Estudos Linguísticos) - Instituto de Biociências, Letras e Ciências Exatas (IBILCE), São José do Rio Preto, São Paulo.

DURAND, Corinne. Certidão de casamento civil expedida em 1859, 2017. Disponível em: 
http://corinne.durand94.free.fr/Dispense_mariage_curieuse.html. Acesso em: 28 nov. 2017.

FRANÇA. Archives de Nantes, 2010. Disponível em:

http://www.archives.nantes.fr/pages/DOSSIERS_DOCS/cimetieres/militaires/ pages/charpentier_francois/charpentier_francois.html. Acesso em: 28 nov. 2017.

FRANÇA. Les livrets de famille, 2013a. Disponível em:

<http://www.diplomatie.gouv.fr/fr/les-francais-a-l-etranger/vos-droits-etdemarches/etat-civil/demarches-relatives-aux-actes-d/article/livrets-defamille>. Acesso em: 18 set. 2013.

FRANÇA. Mariage en France, 2013b. Disponível em: http://www.vosdroits.justice.gouv.fr/. Acesso em: 02 jun. 2013.

FRANÇA. Proclamation de l'an premier de la République, 2017. Disponível em: http://www.gouvernement.fr/partage/9416-la-republique-francaise-estproclamee. Acesso em: 13 out. 2017.

FROESCHLÉ-CHOPARD, Marie-Hélène; FROESCHLÉ-CHOPARD, Michel. Une double image de la Révolution : le calendrier et le mètre. In: Annales historiques de la Révolution française, n. 279, 1990. p. 74-88. Disponível em: http://www.persee.fr/docAsPDF/ahrf_ooo34436_1990_num_279_1_1294.pdf. Acesso em: 10 mar. 2016.

GENEAGROSNE. Certidão de casamento civil expedida em 1802, 2013. Disponível em:

http://www.geneagrosne.org/Colombier_sous_Uxelles/PEC/filatrai.html. Acesso em: 28 ago. 2013.

GENEASERVICE. Certidão de casamento civil expedida em 1837, 2013.

Disponível em: https://www.geneaservice.com/images/fiches/36-acte-mariagetoulon.jpg. Acesso em: 28 ago. 2013.

HOFFMANN, Lothar. Llenguatges d'especialitat. Selecció de textos. In: BRUMME, Jenny. (Org.) Barcelona: IULA/UPF, 1998.

KRIEGER, Maria da Graça; FINATTO, Maria José Bocorny. Introdução à Terminologia: teoria e prática. São Paulo: Contexto, 2004.

MARTINEJUDE. Certidão de casamento civil expedida em 1901, 2013. Disponível em: http://www.martinejude.fr/n223.htm. Acesso em: 21 ago. 2013.

PAVEL, Silvia; NOLET, Diane. Manual de Terminologia. Tradução de Enilde Faulstich. Gatineau: Quebec, 2003. 
PEREIRA, Amanda Henrique; NADIN, Odair Luiz. Análise da variação terminológica denominativa em textos jurídicos: o caso do termo petição inicial. Tradterm, v. 34, p. 121-142, 2019. Disponível em: <http://www.revistas.usp.br/tradterm/article/view/160799/158272>. Acesso em: 25 mar 2020.

SABORIT, Ignasi Terradas. Religiosidade na Revolução Francesa [online]. Rio de Janeiro: Centro Edelstein de Pesquisas Sociais, 2009. Disponível em: http://static.scielo.org/scielobooks/x9qvt/pdf/saborit-9788599662984.pdf. Acesso em 10 mar. 2016.

TARTIER, Annie. Analyse automatique de l'évolution terminologique. In: Actes du Traitement Automatique des Langues Naturelles (TALN), Leuven, 2006. Disponível em:

http://www.revuei3.org/hors_serie/annee2006/revue_i3_hs2006_01_05.pdf. Acesso em: 27 abr. 2016.

Artigo recebido em 18 de maio de 2020 e aceito em 16 de julho de 2020. 